\title{
A Review on the Proposed Quasi-Concave Quadratic Programming Problems with Bounded Variable: by Counter-example, by Computer Algebra
}

\section{H. K. Das}

Department of Mathematics, Dhaka University, Dhaka-1000, Bangladesh

(Received: 3 January 2016; Accepted: 27 March 2017)

\section{Introduction}

Quasi concave quadratic programming (QP) bounded variable problems in which the objective function involve the product of two factorized linear functions and constraints functions are in the form of linear inequalities and the variables are bounded. The purpose of this research is to series of study on nonlinear programming (NLP) problems, QP Problems, linear fractional programming (LFP) problems. In this series study, firstly H. K. Das, and Hasan developed a technique for solving LFP bounded variable problems $^{8}$ in 2012 by following LP bounded variable Problems and in the same time M. B. Hasan developed a technique for solving special type QP Problems ${ }^{2}$. Latter in 2013, H.K. Das and $\operatorname{Hasan}^{3}$ developed a generalized technique for solving unconstrained NLP problems. Again in 2013 H. K. Das and Hasan ${ }^{7}$ improved decomposition approach and its computer technique for solving primal dual LP and LFP problems. In 2014, H.K Das , T. Saha and Hasan $^{5}$ studied on 1-D Simplex Search and its numerical experiments through computer algebra. In 2015 H. K. Das and $\mathrm{Hasan}^{4}$ studied on the algorithmic technique for solving NLP and QP problems. Finally, in 2016 H. K. Das developed a decomposition procedure for solving NLP and QP problems based on Lagrange and Sander's Method. However an algorithm for solving quasi-concave QP bounded variable problems proposed by M. Asadujjaman and Hasan ${ }^{1}$ in 2015. But unfortunately, this proposed method $^{1}$ arises a big question to solve the quasi-concave QPBV problems. So, it becomes very important to study on the quasi-concave QPBV problems.

Therefore, this paper is concerned with the analysis of the proposed algorithm ${ }^{1}$ of paper's concerning of the quasiconcave QP bounded variables problems, failed to solve in this type of problems. A counter example is given to verify the proposed algorithm ${ }^{1}$ and compare the result obtained from the counter example for the proposed algorithm ${ }^{1}$ with the build in command in Mathematica and developed code in Mathematica. Finally, it is suggested that the counter example might be adequate to justify the proposed algorithm ${ }^{1}$.

\section{Experimental}

Numerical Experiment

This Section is designed for the justification of proposed algorithm ${ }^{1}$.

Counter Example 1

This example is taken from Asadujjaman and Hasan ${ }^{1}$.

$\operatorname{Max} z=\left(5 x_{1}+x_{2}+10\right)\left(4 x_{1}+2 x_{2}+12\right)$

Author for correspondence. e-mail: hkdas.rohit@ gmail.com hkdas_math@du.ac.bd subject to:

$5 x_{1}+x_{2}+x_{3}=20$

$4 x_{1}-x_{3}+x_{4}=14$

$2 \leq x_{1} \leq 5,, 4 \leq x_{2} \leq 12,0 \leq x_{3} \leq 25,0 \leq x_{4} \leq 18$

Solution Using Proposed Algorithm ${ }^{l}$

Since $x_{1}$ and $x_{2}$ has positive lower bound so we substituted at its lower bound. Let, $x_{1}=2+y_{1}$, then $0 \leq y_{1} \leq 3$ and $x_{2}=4+y_{2}$, then $0 \leq y_{2} \leq 8$. Substitute these into the above problem we get following

$\operatorname{Max} z=\left(5 y_{1}+y_{2}+24\right)\left(4 y_{1}+2 y_{2}+28\right)$

subject to:

$5 y_{1}+y_{2}+x_{3}=6$

$4 y_{1}-x_{3}+x_{4}=6$

$0 \leq y_{1} \leq 3,0 \leq y_{2} \leq 8,0 \leq x_{3} \leq 25,0 \leq x_{4} \leq 18$

Table 1. Initial Table

\begin{tabular}{|c|c|c|c|c|c|c|}
\hline \multirow[t]{2}{*}{$c_{B}$} & \multirow[t]{2}{*}{$d_{B}$} & $\begin{array}{l}c_{j} \rightarrow \\
d_{j} \rightarrow\end{array}$ & $\begin{array}{l}5 \\
4\end{array}$ & $\begin{array}{l}1 \\
2\end{array}$ & $\begin{array}{l}0 \\
0\end{array}$ & $\begin{array}{l}0 \\
0\end{array}$ \\
\hline & & $x_{B i} \rightarrow$ & $y_{1}$ & $y_{2}$ & $x_{3}$ & $x_{4}$ \\
\hline 1 & 2 & $y_{2}=6$ & (5) & 1 & 1 & 0 \\
\hline 0 & 0 & $x_{4}=6$ & 4 & 0 & -1 & 1 \\
\hline \multirow[t]{4}{*}{$\begin{array}{l}z_{1}= \\
30\end{array}$} & $\begin{array}{l}z^{2}= \\
40\end{array}$ & $\begin{array}{l}z= \\
1200\end{array}$ & & & & \\
\hline & & $c_{j}-z_{j}^{1}$ & 0 & 0 & -1 & 0 \\
\hline & & $d_{j}-z_{j}^{2}$ & -6 & 0 & -2 & 0 \\
\hline & & $\Delta_{j} \longrightarrow$ & $180^{\prime}$ & 0 & 30 & 0 \\
\hline
\end{tabular}

$\theta_{1}=\min \left\{\frac{6}{5}, \frac{6}{4}\right\}=6 / 5$, since $\left(\alpha^{j}{ }_{i}>0, \theta_{2}=\infty\right.$,

$U_{1}=$ upper bound of $y_{1}=3$.

$\theta=\min \left\{\theta_{1}, \theta_{2}, U_{j}\right\}=6 / 5=\theta_{1}$. So the entering

variable is $y_{1}$ in replace of $y_{2}$

In the following table, all $\Delta_{j} \leq 0$ so this table is given the 
optimal solution. Here, the optimal solution is as follows: $x_{1}=2+6 / 5=\frac{16}{5}, x_{2}=4+0=4, x_{3}=0, x_{4}=\frac{6}{5}$ and the optimal value is 984 .

Table 2. Optimal table

\begin{tabular}{|c|c|c|c|c|c|c|}
\hline \multirow{3}{*}{$c_{B}$} & \multirow{3}{*}{$d_{B}$} & $c_{j} \rightarrow$ & 5 & 1 & 0 & 0 \\
\hline & & $d_{j} \rightarrow$ & 4 & 2 & 0 & 0 \\
\hline & & $x_{B i}$ & $y_{1}$ & $y_{2}$ & $x_{3}$ & $x_{4}$ \\
\hline 5 & 4 & $y_{1}=6 / 5$ & 1 & $1 / 5$ & $1 / 5$ & 0 \\
\hline 0 & 0 & $x_{4}=6 / 5$ & 0 & $-4 / 5$ & $-9 / 5$ & 1 \\
\hline $\begin{array}{l}z_{1}= \\
30\end{array}$ & $\begin{array}{l}z^{2}= \\
\frac{164}{5}\end{array}$ & $\begin{array}{l}z= \\
984\end{array}$ & & & & \\
\hline & & $c_{j}-z_{j}^{1}$ & 0 & 0 & -1 & 0 \\
\hline & & $d_{j}-z_{j}^{2}$ & 0 & $6 / 5$ & $-4 / 5$ & 0 \\
\hline & & $\Delta_{j} \longrightarrow$ & 0 & -36 & $-44 / 5$ & 0 \\
\hline
\end{tabular}

\section{Results and Discussion}

Following table observes that the coding output, build in command output and exact results are identical, but the proposed algorithm ${ }^{1}$ is not identical with the exact solution.

\section{Table 3. Result comparison}

\begin{tabular}{|l|l|}
\hline Method & Results \\
\hline $\begin{array}{l}\text { Original } \\
\text { Problem }\end{array}$ & $\begin{array}{l}\text { Optimal value: } 1200 \\
\text { Optimal solution: }\{2,10,0,6\} \\
\text { Comments: Exact solution }\end{array}$ \\
\hline $\begin{array}{l}\text { Proposed } \\
\text { algorithm }\end{array}$ & $\begin{array}{l}\text { Optimal value: } 978 \\
\text { Optimal } \quad \text { solution: } \quad\left\{\frac{16}{5}, 4,0, \frac{6}{5}\right\}\end{array}$ \\
& $\begin{array}{l}\text { Comments: Not identical with exact } \\
\text { solution }\end{array}$ \\
\hline $\begin{array}{l}\text { Mathemat } \\
\text { ica Code }\end{array}$ & $\begin{array}{l}\text { Optimal value: } 1200 \\
\text { Optimal solution: }\{2,10,0,6\} \\
\text { Comments: Identical with exact solution }\end{array}$ \\
\hline $\begin{array}{l}\text { Build in } \\
\text { Command }\end{array}$ & $\begin{array}{l}\text { Optimal value: } 1200 \\
\text { Optimal solution: }\{2,10,0,6\} \\
\text { Comments: Identical with exact solution }\end{array}$ \\
\hline
\end{tabular}

In page 114, example 2, addressed as counter example-1 i the current paper is failed. In page 116, reference Mathematica "Output for Numerical Example 2" is not optimal solution for the quasi-concave QP problem. The possible all basic solution is given in the following table.
Table 4. All basic solution for numerical example-2 ref $^{1}$

\begin{tabular}{|l|c|}
\hline All Possible basic solution & Obj. function value \\
\hline$\{2,4,6,12,0,3,0,8,19,6\}$ & 672 \\
\hline$\left\{\frac{16}{5}, 4,0, \frac{16}{5}, \frac{6}{5}, \frac{9}{5}, 0,8,25, \frac{84}{5}\right\}$ & 984 \\
\hline$\{2,10,0,6,0,3,6,2,25,12\}$ & 1200 \\
\hline
\end{tabular}

Therefore the optimal solution is $\quad\{2,10,0,6,0,3,6,2,25,12\}$ and the optimal value is 1200 . However, in reference ${ }^{1}$, on page 116, "Output for numerical example 2", the optimal value the quasi-concave QP is 984 and optimal solution is $\left\{\frac{16}{5}, 4,0, \frac{16}{5}, \frac{6}{5}, \frac{9}{5}, 0,8,25, \frac{84}{5}\right\}$.

\section{Conclusion}

The aim of the research was to study a series of study on NLP problems, QP Problems, LFP problems and quasiconcave QPBV problems. We then found that proposed quasi-concave QPBV algorithm ${ }^{1}$ was failed to solve in this type of problem. A counter example was given to demonstrate this argument. A computer technique also introduced by using programming language Mathematica for quasi-concave QPBV problems. We therefore, hope that that the counter example might be adequate to justify the proposed algorithm ${ }^{1}$.

\section{References}

1. Asaduijaman M. and M. B. Hasan, 2015. A proposed technique for solving quasi-concave QP problems with bounded variables, Dhaka Univ. J. Sci., 63(2), 111-117.

2. Hasan M. B., 2012. A Technique for Solving Special Type QP Problems, Dhaka Univ. J. Sci., 60(2), 209-215.

3. Das H. K., 2017. A Procedure for Solving Quadratic Programming Problems Dhaka Univ. J. Sci., 65(1), 9-13.

4. Das H. K. and M. B. Hasan, 2015. An algorithmic technique for solving non-linear programming and quadratic programming problems. GANIT, Journal Bangladesh Mathematical Society,

5. Das H.. K., T. Saha and M. B. Hasan, 2014. A Study on 1-D Simplex Search and its Numerical Experiments through Computer Algebra. Dhaka University Journal of Science, 62(2), 95-102.

6. Das H. K. and M. B. Hasan, 2013. A Generalized Technique for Solving Unconstrained Non-Linear Programming Problems. Dhaka University Journal of Science, 61(1), 75-80.

7. Das H. K. and M. B. Hasan, 2013. An improved decomposition approach and Its Computer Technique for Solving Primal Dual LP \& LFP Problems. GANIT, Journal Bangladesh Mathematical Society, 33, 65-75.

8. Das H. K. and M. B. Hasan, 2012. A Proposed Technique for Solving Linear Fractional Bounded Variable Problems, Dhaka University Journal of Science, 60(2), 223-230.

9. Das H. K., 2016. Decomposition Procedure for Solving NLP and QP Problems Based on Lagrange and Sander's Method, International Journal of Operations Research and Information Systems, 7(4), 67-93. 